\title{
Esperamicin Antibiotic
}

National Cancer Institute

\section{Source}

National Cancer Institute. Esperamicin Antibiotic. NCl Thesaurus. Code C148123.

Any agent belong ing to the esperamicins, a class of bacterium-derived chromoprotein

enediyne antibiotics with antineoplastic activity. Esperamicins bind to the minor groove of DNA, cleave DNA and induce apoptosis of tumor cells. 